University of Nebraska - Lincoln

DigitalCommons@University of Nebraska - Lincoln

1999

\title{
Survival and Physiologic Response of Common Amakihi and Japanese White-Eyes During Simulated Translocation
}

Thierry M. Work

U.S. Geological Survey, thierry_work@usgs.gov

J. Gregory Massey

Hawaii Division of Forestry and Wildlife

Luanne Johnson

U.S. Geological Survey

Steve Dougill

U.S. Geological Survey

Paul C. Banko

U.S. Geological Survey

Follow this and additional works at: https://digitalcommons.unl.edu/usgsstaffpub

Work, Thierry M.; Massey, J. Gregory; Johnson, Luanne; Dougill, Steve; and Banko, Paul C., "Survival and Physiologic Response of Common Amakihi and Japanese White-Eyes During Simulated Translocation" (1999). USGS Staff -- Published Research. 638.

https://digitalcommons.unl.edu/usgsstaffpub/638

This Article is brought to you for free and open access by the US Geological Survey at DigitalCommons@University of Nebraska - Lincoln. It has been accepted for inclusion in USGS Staff -- Published Research by an authorized administrator of DigitalCommons@University of Nebraska - Lincoln. 


\title{
SURVIVAL AND PHYSIOLOGIC RESPONSE OF COMMON AMAKIHI AND JAPANESE WHITE-EYES DURING SIMULATED TRANSLOCATION ${ }^{1}$
}

\author{
THIERRY M. WORK \\ U.S. Geological Survey, Biological Resources Division, National Wildlife Health Center, Honolulu Field \\ Station, P.O. Box 50167, Honolulu, HI 96850, e-mail: thierry_work@usgs.gov
}

\section{J. GRegory MASSEY}

Hawaii Division of Forestry and Wildlife, 2600 Piiholo Rd., Makawao, HI 96768

\author{
Luanne Johnson, Steve Dougill and Paul C. Banko \\ U.S. Geological Survey, Biological Resources Division, Pacific Island Ecosystems Research Center, \\ P.O. Box 44, Hawaii Volcanoes National Park, HI 96718
}

\begin{abstract}
We evaluated the effects of three translocation trials on Common Amakihi (Hemignathus virens) and Japanese White-eyes (Zosterops japonicus). Trial 1 involved capturing birds, transporting them on rough roads for $4 \mathrm{hr}$ followed by holding in an aviary for $48 \mathrm{hr}$ without overnight thermal support prior to release. Trial 2 involved capture, then holding in an aviary for $48 \mathrm{hr}$ with overnight thermal support followed by transport for 4 hr prior to release. Trial 3 and 1 were identical except that overnight thermal support was provided during trial 3 . We monitored survival, food consumption, weight change, and fecal production during captivity as well as changes in hematocrit, estimated total solids, heterophil to lymphocyte ratios, plasma uric acid, and creatinine phosphokinase (CPK) at capture and release. Survival was significantly lower for Amakihi during trial 1 (no thermal support). Birds that died lost significantly more weight than those that survived. Regardless of trial, birds responded to translocation by a combination of weight loss, anemia, hypoproteinemia, and elevated heterophil to lymphocyte ratio, uric acid, and CPK levels. The first $24 \mathrm{hr}$ of captivity posed the greatest risk to birds regardless of whether transport or holding occurred first. Food consumption, fecal production, and weight all decreased at night, and overnight thermal support during holding was critical if ambient temperatures dipped to freezing. We recommend that if small passerines are to be held for $>12 \mathrm{hr}$, they be monitored individually for weight loss, food consumption, and fecal production.
\end{abstract}

Key words: Common Amakihi, Hemignathus virens, Japanese White-eye, physiology, translocation, Zosterops japonicus.

\section{INTRODUCTION}

Translocation is one of many tools for preservation and enhancement of endangered birds (Jackson et al. 1983, Griffith et al. 1989, Wolf et al. 1996). However, most studies investigating translocation of passerines focus on survival post-release. There is little information on the physiologic effects of translocation on birds. Scott and Carpenter (1987) recognized the paucity of objective data on avian translocation. This lack of knowledge assumes greater importance in endangered birds because the loss of each individual during translocation assumes greater proportional importance to the whole population.

Understanding the physiologic effects of

\footnotetext{
${ }^{1}$ Received 5 April 1998. Accepted 14 October 1998.
}

translocation on small passerines may elucidate risk factors and enable more effective intervention or management to increase survival prior to release. Several blood parameters can indicate whether birds are stressed, dehydrated, or undergoing negative energy balance during translocation. For example, elevations of hematocrit and estimated total solids may be an indication of dehydration (Quesenberry and Hillyer 1994). Increased plasma uric acid may indicate a bird on a high protein diet, renal disease, or dehydration, whereas increased plasma creatinine phosphokinase may indicate excessive skeletal muscle breakdown (Hochleithner 1994). Elevated heterophil to lymphocyte ratios in birds are a common manifestation of stress (Gross and Siegel 1983) or inflammation (Campbell 1994).

This study evaluated the physiologic effects of different translocation trials on two common 
species of forest birds in Hawaii in order to develop guidelines for translocation of endangered species.

\section{METHODS}

We used three translocation trials. Trial 1 involved capture, transport on rough roads for 4 $\mathrm{hr}$, and holding in an aviary for $48 \mathrm{hr}$ without overnight thermal support prior to release. Trial 2 involved capture, then holding with overnight thermal support for $48 \mathrm{hr}$ followed by transport for $4 \mathrm{hr}$ prior to release. Trial 3 was identical to trial 1 except that overnight thermal support was provided.

We used Common Amakihi (Hemignathus virens) and Japanese White-eyes (Zosterops japonicus) as surrogates for endangered passerines because both were small $(<15 \mathrm{~g})$ and common in the study site. Common Amakihi are endemic Hawaiian honeycreepers and members of a subfamily containing 14 endangered taxa. Japanese White-eyes (Zosteropidae) are an introduced species that is widespread in Hawaiian forests and other habitats. Both species forage for insects and nectar in Sophora chrysophylla (Fabaceae) and Myoporum sandwicense (Myoporaceae) trees that dominate the dry subalpine woodland study site on the west slope of Mauna Kea volcano, Hawaii (Scott et al. 1986). We endeavored to capture 10 of each species for each trial during 4-13 December 1996.

\section{CAPTURE AND BLEEDING}

We captured birds with mist nets which were opened at 07:30, checked every 10-15 min, and closed at 12:00 (trial 1 and 3) or 14:00 (trial 2) to allow birds $>1 \mathrm{hr}$ of daylight to acclimate to the aviary.

When birds were extracted from nets, time was recorded to the nearest minute using synchronized watches, colored bands and U.S. Fish and Wildlife Service bands were attached, and culmen and tarsus lengths (nearest $0.1 \mathrm{~mm}$ ) and wing chord (nearest $\mathrm{mm}$ ) were measured. Amikihi were aged according to plumage; we were unable to age white-eyes. We placed birds in tared cotton bags and weighed them (nearest 0.1 g) on an electronic scale. We recorded weights at capture, prior to transport, prior to transfer to the aviary, and prior to release. Designated personnel scored fat reserves on a scale of 0 to 4 at capture and at release (Pyle et al. 1987).

After banding and weighing, we took $0.1 \mathrm{cc}$ of blood from the jugular vein with a sterile 1 cc heparinized syringe and a 28 gauge $13 \mathrm{~mm}$ needle. This was followed by a subcutaneous injection of a $24 \mathrm{hr}$ maintenance dose $\left(50 \mathrm{ml} \mathrm{kg}^{-1}\right)$ of lactated ringers solution either in the medial thigh or between the shoulder blades (Quesenberry and Hillyer 1994). Birds were bled again prior to release, but no fluid was given. After bleeding, we offered nectar (Nectar 15, Rowdybush, Sacramento, California). Birds were then held individually in weighing bags in a warm area for $<2 \mathrm{hr}$ prior to holding or transport. Time was recorded at the start and end of transport and holding, and at bleeding and release.

\section{TRANSPORT}

Transport cages consisted of a wooden box subdivided into four $10.5 \times 20 \times 14.5 \mathrm{~cm}$ compartments each housing a single bird. The rear of each compartment had a small screen window for observation, and a small hole to allow placement of a nectar tube. During transport, a person stabilized the cages which were suspended by elastic cord and darkened with cloth to keep birds calm. Every $50 \mathrm{~min}$, the vehicle was stopped and nectar offered to each bird for 10 min. After each transport, boxes were disinfected with dilute quaternary ammonium compound.

\section{AVIARY}

Screened holding cages measured $10 \times 45 \times 25$ $\mathrm{cm}$, weighed $<800 \mathrm{~g}$, and were supplied with perches, nectar tubes, and food cups. Feces were collected on a sheet of paper taped to the outside of the hardware-mesh cage floor. We placed cages on shelves in a $2.4 \mathrm{~m}^{3}$ aviary that was sheltered by tarps during the night. For trials 2 and 3 , a small space heater and two heat lamps powered by generators provided overnight thermal support. Empty holding cages were weighed before and after bird occupancy. Birds were offered finely chopped fruit in a pre-weighed paper food cup and nectar in a nectar tube fastened to the cage wall.

We made daily aviary checks at $07: 00$ and 16 : 00 during which we weighed the cage and bird, minus spilled food, food cup, nectar, and paper. The initial cage weight was subtracted from this weight to obtain the bird's weight. After recording nectar level, we cleaned and replenished 
nectar tubes, provided a new cup of fresh fruit, and replaced the floor paper.

Fruit consumption was calculated by weighing residual fruit and subtracting from initial weight. We calculated nectar consumption using the formula for volume of a cylinder $\left(\pi r^{2} h\right)$ where $h$ was the level of nectar consumed in $\mathrm{mm}$ and $\mathrm{r}$ was the radius of the nectar tube (12.5 $\mathrm{mm})$. Fecal droppings on the floor paper were counted and classified according to percent urate composition $(<25 \%, 25-75 \%$, or $>75 \%$ urates). Between trials, holding cages were disinfected with dilute quaternary ammonium compounds.

We also made aviary checks at 22:00 and 02: 00 to assess effects of overnight temperature on captive birds. We recorded temperature using thermometers located at the front and rear of the aviary; aviary temperature was taken for the second night only in trial 1. A puff score indicating degree of feather fluffing (0-no fluffing, 1moderate fluffing, 2-marked fluffing) was assigned to each bird to determine the severity of response to night-time temperatures. Daily maximum and minimum ambient temperature were recorded outside the aviary with a sheltered $\mathrm{max} / \mathrm{min}$ thermometer.

Birds were removed from the aviary and given supportive care if they were not perched and had a puff score of 2 . Supportive care involved a combination of placing the bird in a brooder at $28^{\circ} \mathrm{C}$, offering nectar and fruit, gavage with warm nectar, subcutaneous administration of lactated ringers, and intramuscular administration of $10 \mathrm{mg} \mathrm{kg} \mathrm{g}^{-1}$ prednisolone sodium succinate or $0.3 \mathrm{ml} \mathrm{kg}^{-1}$ Injacom-100 (a vitamin supplement). Birds were returned to the aviary once they were able to perch and feed on nectar.

\section{CLINICAL AND ANATOMIC PATHOLOGY}

Thin blood smears were made in duplicate immediately after collection and remaining blood was stored at $4^{\circ} \mathrm{C}$ in heparinized capillary tubes for up to $8 \mathrm{hr}$. We obtained hematocrit (\%) with a centrifuge and estimated total plasma solids $\left(\mathrm{mg} \mathrm{dl}^{-1}\right)$ with a temperature adjusted refractometer (Campbell 1994). Plasma was stored in cryovials at $-196^{\circ} \mathrm{C}$. Smears were stained with a Wright's-Romanowsky stain, and 200 white cells counted for differential. Creatinine phosphokinase (CPK) $\left(\mathrm{IU} \mathrm{l}^{-1}\right)$ and uric acid $\left(\mathrm{mg} \mathrm{dl}^{-1}\right)$ were determined using a Vettest 8008 (IDEXX,
Westbrook, Maine) automated chemistry analyzer.

We performed a complete external and internal examination on birds that died. Brain, skeletal muscle, bone marrow, liver, kidney, spleen, gastrointestinal tract, heart, and lung were fixed in $10 \%$ formalin, embedded in paraffin, sectioned at $5 \mu \mathrm{m}$, and stained with hematoxylin and eosin for histology.

\section{DATA ANALYSIS}

For each bird in each trial, we calculated minutes spent in weighing bag (minutes in bag). Percent weight change during transport was calculated using weights at start and end of transport. Percent weight change during holding was calculated using weight at start and end of holding. Percent weight change during captivity was calculated using capture and release weights. Percent change in hematocrit, estimated total solids, plasma uric acid, CPK, and heterophil to lymphocyte ratio were calculated using values from capture and release blood samples.

Because of the dry climate at the study site, we evaluated the effect of desiccation on changes in fruit weight by measuring weight loss of 10 dishes of fruit over $8 \mathrm{hr}$. We used this value to correct food consumption for desiccation.

Because fluctuations in humidity throughout the day may have affected cage weights, we calculated the hourly change in cage weight during each daily aviary check interval. We used this value to correct each bird weight, and corrected bird weights were used to calculate percent hourly change in weight.

We used Student's $t$-test or one-way analysisof-variance for pair-wise or multiple comparisons, respectively. We used the Mann-Whitney $U$-test or the Kruskal Wallis one-way ANOVA for data that did not fit assumptions of normality or equal variance (Daniel 1987). To maintain an experiment-wide level of significance at 0.05 , we adjusted alpha using the Bonferroni test (alpha $\mathrm{n}^{-1}$ ) with $\mathrm{n}$ being the number of analytes being compared (Rice 1989). In case of significant differences for ANOVA, pair-wise comparisons were made using Student-Neuman-Keuls test with $\alpha=0.05$.

We compared survival between trials for each species separately using Chi square tests. To evaluate the effect of time of day of capture on capture weight of birds (pooled live, dead, and escaped birds from all trials), we used simple 
TABLE 1. Percent change in physiological variables of Common Amakihi and Japanese White-eyes that survived during 3 simulated translocation trials. Values are $\bar{x} \pm \mathrm{SD}(n) .^{\mathrm{a}}$

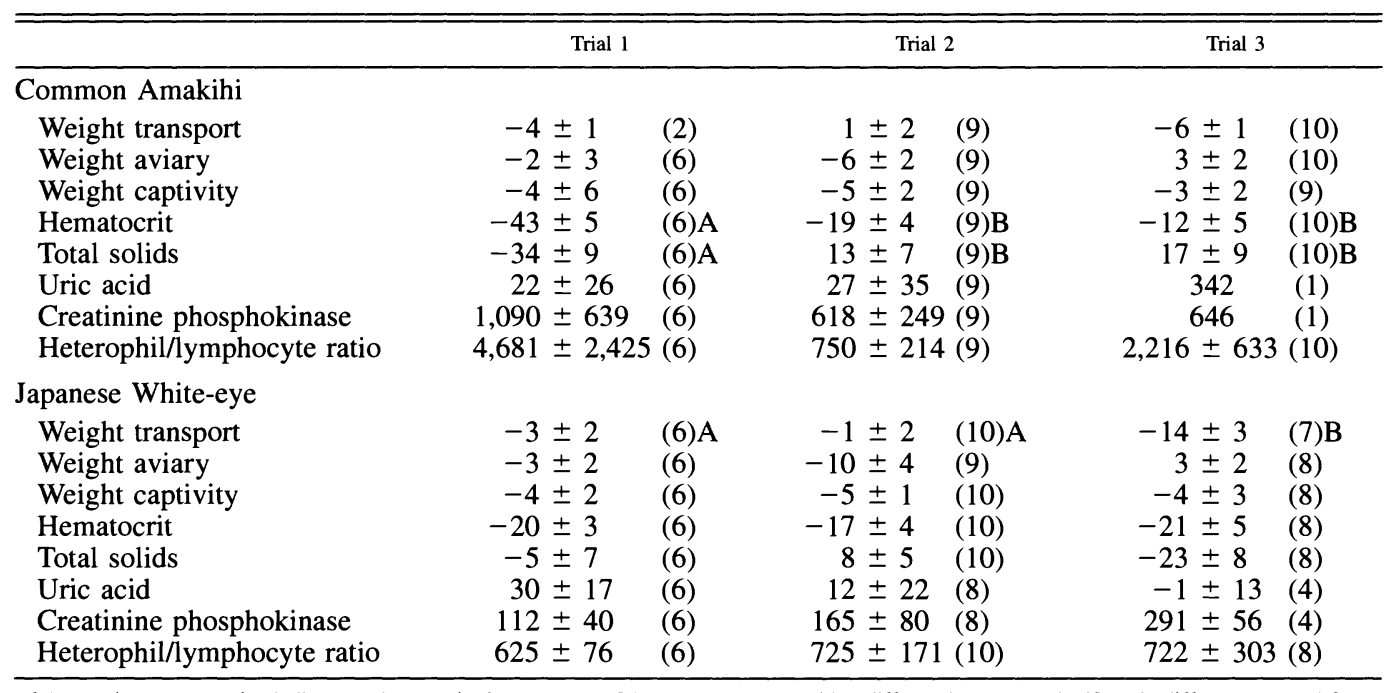

${ }^{a}$ A negative percent value indicates a decrease in that parameter. Means across a row with a different letter were significantly different at $P<0.01$.

linear regression. Alpha for both tests was 0.05 based on two-tailed comparisons.

\section{RESULTS}

We caught 10 White-eyes and 10 Amakihi over two days for trial 1 , and 10 of each species in one day for trials 2 and 3. Survival for Amakihi was $60 \%, 90 \%$, and $100 \%$ for trials 1,2 , and 3 , respectively; survival for white-eyes was $60 \%$, $90 \%$, and $89 \%$ for trials 1,2 , and 3, respectively. Hatch-year birds comprised a majority (60\%) of Amakihi caught in trials 1 and 3. One white-eye escaped during trial 3 . Survival was significantly lower for Amakihi during trial $1\left(\chi^{2}{ }_{2}=6.2, P\right.$ $<0.05)$. Percent change in hematocrit was significantly greater for Amakihi $\left(t_{11}=3.83, P<\right.$ 0.01 ) than white-eyes in trial 1 . Amakihi also had significantly higher percent change in uric acid $(T=13, P<0.01)$ than white-eyes in trial 3.

For Amakihi, percent change in hematocrit $\left(F_{2,22}=9.8, P<0.001\right)$ and estimated total solids $\left(F_{2,22}=9.5, P<0.001\right)$ was significantly greater in trial 1 (Table 1). For white-eyes, 6 birds in trial 1 were held in weighing bags for $47 \pm 3 \mathrm{~min}$ which was a significantly $\left(\mathrm{H}_{2}=\right.$ 13.6, $P<0.001)$ shorter time than 10 and 8 white-eyes in trials $2(85 \pm 3 \mathrm{~min})$ and $3(68 \pm$ $7 \mathrm{~min}$ ), respectively. White-eyes in trial $3 \mathrm{had}$ significantly greater weight loss during transport $\left(F_{2,20}=10.2, P<0.001\right)$ (Table 1$)$. Weight at capture increased significantly with time of day in Amakihi $\left(r_{28}=0.43, P<0.05\right)$ but not whiteeyes.

For both species in all trials, hourly food consumption and fecal production decreased while percent hourly weight loss increased at night (Fig. 1). Percent of feces containing $<25 \%$ urates increased with holding time but decreased towards the end of holding for trials 2 and 3 . Feces containing $>75 \%$ urates followed an opposite pattern with a progressive decrease and an increase near the end of the holding period. We saw no consistent pattern for feces classified as $25-75 \%$ urates (Fig. 1). Fruit left in dishes for $8 \mathrm{hr}$ lost an average of $1 \pm 0.1 \%$ of their weight $\mathrm{hr}^{-1}$.

Heat lamp and heaters kept aviary temperatures $(\bar{x} \pm \mathrm{SD}[n]) 7 \pm 3^{\circ} \mathrm{C}$ (10) higher than night-time ambient $\left(0 \pm 2^{\circ} \mathrm{C}\right.$ [9]); day time temperatures averaged $18 \pm 2^{\circ} \mathrm{C}(9)$. Percent weight loss $(\bar{x} \pm \mathrm{SE}[n])$ for Amakihi was significantly greater in birds that died (15 $\pm 2 \%$ [5]) vs. those that survived $(4 \pm 2 \%[24])(T=126, P<$ $0.005)$. Percent weight loss for white-eyes that died $(23 \pm 2 \%$ [4]) versus those that survived $\left(5 \pm 1 \%\right.$ [24]) also was significantly greater $\left(t_{26}\right.$ $=6.4, P<0.001)$.

One white-eye died shortly following collection of an initial blood sample. On necropsy, the animal had ample fat reserves, severe subcutaneous hemorrhage at the venipuncture site, and severe diffuse pulmonary congestion. Gross pa- 

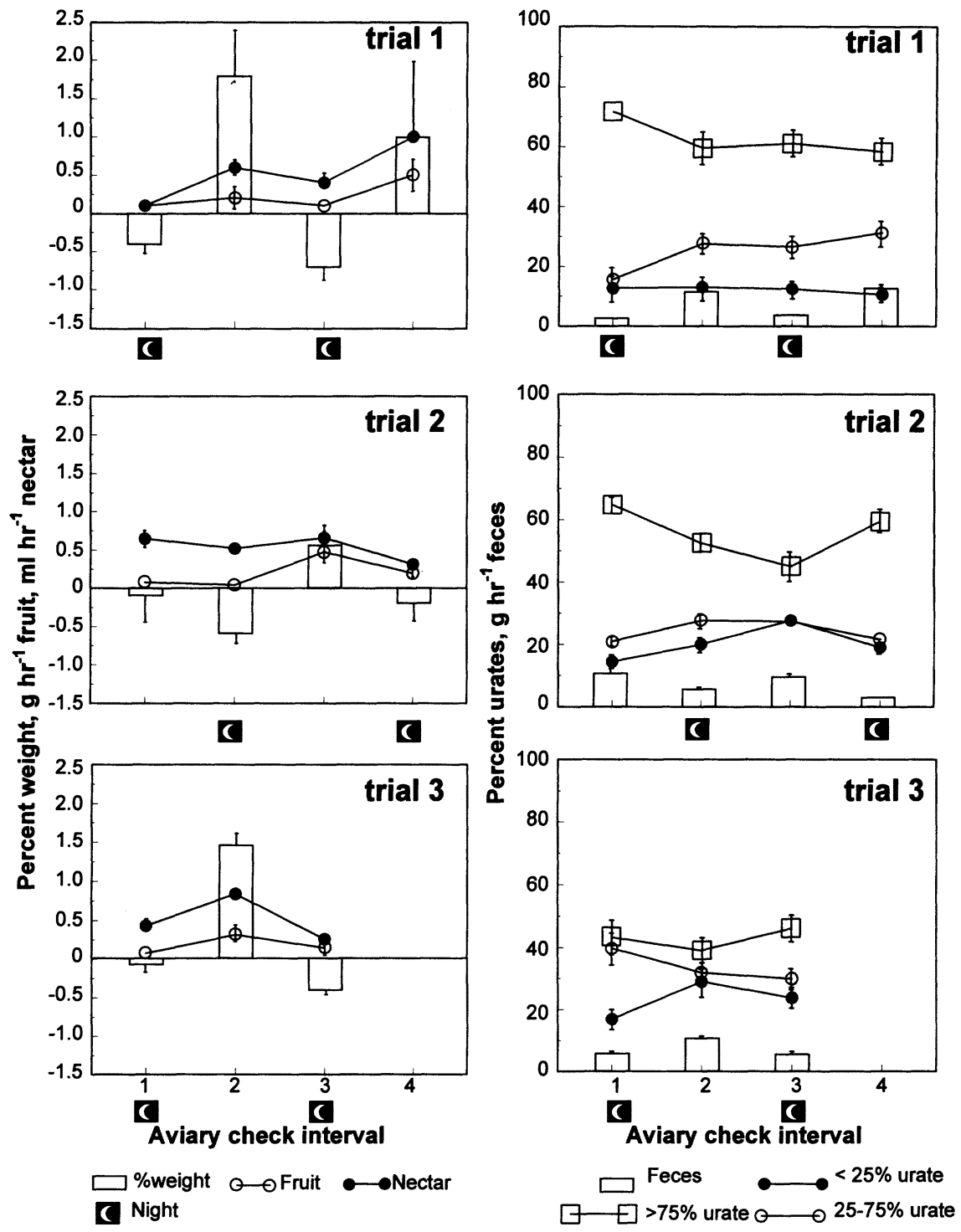

FIGURE 1. For pooled Amakihis and Japanese White-eyes during each aviary check interval: mean ( \pm SE) percent: hourly weight change, $\mathrm{ml} \mathrm{hr}^{-1}$ of nectar and $\mathrm{g} \mathrm{hr}^{-1}$ of fruit consumed, hourly fecal production, and urate composition for trials $1-3$. Negative values indicate a percent weight loss.

thology for all other birds revealed an almost complete lack of body fat, pale and tacky dry musculature and internal organs, and the entire gastrointestinal tract coated with small amounts of bile stained mucus. Histology revealed moderate to severe atrophy of spleen, liver, and pancreas, accumulation of hemosiderin in liver, and marked depletion of bone marrow red cell precursors. Mild, focal, acute necrosis and hemorrhage were seen in kidney, liver, or skeletal mus- cle of three birds. No inflammation or infectious organisms were observed.

\section{DISCUSSION}

All mortalities occurred during the first $24 \mathrm{hr}$ of captivity regardless of trial. Lack of overnight thermal support probably accounted for decreased survival in trial 1 . This was confirmed by repeating this trial with overnight thermal support which resulted in increased survival. 
Most likely, near freezing night-time temperatures induced birds to torpor with consequent inability to feed or thermoregulate culminating in death. Ketterson and King (1977) found similar phenomena in White-crowned Sparrows (Zonotrichia leucophrys gambelii) experimentally exposed to fasting and low temperatures. Chaplin (1974) noted that Black-capped Chickadees ( $\mathrm{Pa}$ rus atricapillus) reduce their metabolic expenditure and body temperature when exposed to freezing ambient temperature overnight. In our study, maintaining night time aviary temperatures at $4-8^{\circ} \mathrm{C}$ appeared to increase survival. Birds had little trouble thermoregulating during the day when temperatures reached $15-18^{\circ} \mathrm{C}$; we base this conclusion on increased food consumption and weight gain during daylight hours. Ketterson and King (1977) report increased metabolic rate during the day in captive Whitecrowned Sparrows, and Chaplin (1974) found a similar phenomenon in chickadees.

Because death in captive small passerines can occur rapidly ( $<24 \mathrm{hr}$ ), it is critical that weight, food consumption, and fecal production for individual birds be closely monitored, particularly if animals are to be held overnight. Food consumption served as a valuable adjunct to monitoring weight loss. For example, some birds that survived lost as much as $2 \%$ of their body weight per hour over a 16-hr period but would invariably gain weight in the subsequent period if they ate. Hourly fecal production also indicated if birds were eating; however, fecal composition (percent urates) was more variable. Although feces classified as $<25 \%$ or $>75 \%$ urates served as crude guides to indicate whether birds were calorie deficient, we saw little value in classifying feces as $25-75 \%$ urates. We found that offering both nectar and fruit to both species was important because some individuals appeared to intermittently prefer one or the other.

Factors such as age, capture weight, fat score, or holding time did not influence survival in this study. We cannot explain why shorter holding time in weighing bags in trial 1 would account for lower survival in white-eyes. Inability to detect significant difference in other parameters between trials can be partly attributed to small sample size. Because capture weight increases with time of day in Amakihi, this may be used to beneficial effect during translocations in that birds caught later in the day would start the capture/translocation process with greater reserves.
Based on mortality and weight loss, transport provided relatively little risk to birds. The significantly higher weight loss during transport in trial 3 for white-eyes may have been due to low nectar consumption, but spillage of nectar during transport precluded accurate calculations of nectar consumption. Alternatively, excessive activity of white-eyes also may explain significant weight loss at transport for trial 3 . Although the small size of transport compartments were designed to discourage movement, activity level varied. Quantifying activity during transport may help explain differences in weight loss during this treatment in future studies. Weight loss during transport for both species was greater for trials 1 and 3 where transport was the first treatment after captivity. It is likely that acclimation to captivity contributed to lower transport weight loss in trial 2.

Amakihis and white-eyes responded to translocation through weight loss, anemia, hypoproteinemia, hyperuricemia, hypercreatinemia, and heterophilia. Clinical pathology changes in the larger Amakihi, particularly in hematocrit and uric acid, were usually more pronounced than those of smaller white-eyes. Lower survival for Amakihi during trial 1 also suggested this species was more sensitive to translocation than white-eyes. Kendeigh (1969) noted that larger birds withstand fasting longer than smaller birds. The Common Amakihi is heavier than the Japanese White-eye and presumably should be more resistant to fasting, however we are cautious about drawing such conclusions on a limited sample size using species of similar weight. Kendeigh (1969) examined time to death to evaluate relative ability of different sized birds to withstand fasting. Clinical pathologic response in fasting birds of differing weight may not follow the same pattern as time to death.

Anemia in both species was due to bone marrow exhaustion. We based this conclusion on histologic evidence of depletion of marrow redcell precursors in birds that died. Other than one bird which had a very low parasitemia with Plasmodium sp., we saw no evidence of other causes of anemia such as excessive blood loss, chronic inflammation, or blood parasites (Campbell 1994). Based on initial weights and hematology, it is unlikely that birds were nutritionally compromised at capture, thus ruling out predisposing deficiencies such as iron or vitamin B1 (Campbell 1994). Hypoproteinemia was proba- 
bly secondary to catabolism of body protein stores as evidenced by weight loss and atrophy of internal organs. We saw no evidence of renal or gastrointestinal disease that could account for protein loss through these routes. Catabolism of body protein stores also would account for hyperuricemia and elevated CPK (Hochleithner 1994). Histology did not incriminate renal disease as a cause of hyperuricemia. Hemoconcentration could explain elevated uric acid and CPK levels. Heterophilia is a common manifestation of stress in birds (Gross and Siegel 1983).

We suspect that birds that died in captivity quickly catabolized available fat stores and then proteins. Because insufficient food was consumed, continued catabolism of protein led to hyperuricemia and hypercreatinemia. Subsequent atrophy of internal organs, including liver, led to inability to generate plasma proteins and hypoproteinemia. Insufficient protein was probably responsible for bone marrow atrophy and subsequent anemia. This led to weakness, inability to feed, dehydration, and hemoconcentration with further elevations of CPK and uric acid, and eventually, death. Jordan (1953) also noted atrophy of internal organs in mallards experimentally exposed to starvation but did not measure clinical pathologic parameters.

When translocating small passerines, transporting to the release site immediately after capture may be the safest option. If birds are to be held beyond $12 \mathrm{hr}$, it is critical that they be individually monitored regularly. We judge that housing birds in groups in aviaries will make such monitoring problematic. Housing birds individually allows for more precise monitoring, minimizes competition for space and food resources, and facilitates manipulation for examination or release. In particular, these considerations should be carefully evaluated when endangered birds are translocated.

\section{ACKNOWLEDGMENTS}

We sincerely appreciate the invaluable and dedicated assistance of personnel of the Palila Field Crew and USGS-PIESC who helped make this project a reality. We are grateful to Steve Fancy, Mark Drew, and F.
Josh Dein for providing constructive comments on the manuscript.

\section{LITERATURE CITED}

CAMPBell, T. W. 1994. Hematology, p. 176-198. In B. W. Ritchie, G. J. Harrison, and L. R. Harrison [eds.], Avian medicine, principles and applications. Wingers Press, Lake Worth, FL.

Chaplin, S. B. 1974. Daily energetics of the Blackcapped Chickadee, Parus atricapillus, in winter. J. Comp. Physiol. 89:321-330.

DANIEL, W. W. 1987. Biostatistics: a foundation for analysis in the health sciences. John Wiley and Sons, New York.

Griffith, B., J. M. Scott, J. W. Carpenter, and C. REED. 1989. Translocation as a species conservation tool: status and strategy. Science 245:477480.

Gross, W. B., AND H. S. Siegel. 1983. Evaluation of heterophil/lymphocyte ratio as a measure of stress in chickens. Avian Dis. 27:972-979.

HOCHLEITHNER, M. 1994. Biochemistries, p. 223-245. In B. W. Ritchie, G. J. Harrison, and L. R. Harrison [eds.], Avian medicine, principles and applications. Wingers Press, Lake Worth, FL.

JaCKSON, J. A., B. J. SCHARDIEN, AND P. R. MiLler. 1983. Moving Red-cockaded Woodpecker colonies: relocation or phased destruction? Wildl. Soc. Bull. 11:59-62.

JORDAN, J. S. 1953. Effects of starvation on wild mallards. J. Wildl. Manage. 17:304-310.

KendeIGH, S. 3. 1969. Tolerance of cold and Bergmann's rule. Auk 86:13-25.

KetTerson, E. D., AND J. R. KING. 1977. Metabolic and behavioral responses to fasting in Whitecrowned Sparrows (Zonotrichia leucophrys gambelii). Physiol. Zool. 50:115-179.

Pyle, P., S. N. G. Howell, R. P. YUNICK, AND D. F. DESANTE. 1987. Identification guide to North American passerines. Slate Creek Press, Bolinas, CA.

QuesenberRy, K. E., AND E. V. Hillyer. 1994. Supportive care and emergency therapy, p. 382-416. In B. W. Ritchie, G. J. Harrison, and L. R. Harrison [eds.], Avian medicine, principles and applications. Wingers Press, Lake Worth, FL.

RICE, W. R. 1989. Analyzing tables of statistical tests. Evolution 43:223-225.

ScotT, J. M., S. MountaINSPRING, F. L. Ramsey, AND C. B. KePLER. 1986. Forest bird communities of Hawaiian Islands: their dynamics, ecology and conservation. Stud. Avian Biol. 9:1-431.

SCOTT, J. M., AND J. W. CARPENTER. 1987. Release of captive-reared or translocated endangered birds: what do we need to know? Auk 104:544-545.

Wolf, C. M., B. Griffith, C. ReED, AND S. A. Temple. 1996. Avian and mammalian translocations: update and reanalysis of 1987 survey data. Conserv. Biol. 10:1142-1152. 